\title{
Peranan Kantor Urusan Agama (KUA) Dalam Penguatan Ketahanan Keluarga di Kecamatan Tepus
}

\author{
Iin Suny Atmaja ${ }^{1}$, Andrie Irawan ${ }^{2 *}$, Zainul Arifin ${ }^{3}$, Ihab Habudin ${ }^{4}$, \\ Nur Mukhlish Zakariya ${ }^{5}$, Syawal Rusmanto ${ }^{6}$ \\ ${ }^{123}$ Universitas Cokroaminoto Yogyakarta, ${ }^{4}$ UIN Sunan Kalijaga, \\ ${ }^{5}$ UIN Sunan Ampel, ${ }^{6}$ KUA Kecamatan Tepus Kabupaten Gunung Kidul \\ *Penulis Koresponden, email: andrie.ir@gmail.com
}

\begin{abstract}
Abstrak
Penelitian ini berkaitan dengan peran KUA dalam perwujudan ketahanan keluarga (tahaga) dalam kehidupan masyarakat muslim kecamatan Tepus di Kabupaten Gunung Kidul. Manfaatnya bisa dirasakan dalam pemetaan faktor eksternal ketahanan keluarga yang bisa berpengaruh dalam tahaga termasuk kondisi sosial dan partisipasi masyarakat. Dilihat dari sifatnya, penelitian sosio yuridis kualitatif ini termasuk penelitian deskriptif yang bermaksud dalam pemberian data yang seteliti mungkin tentang kondisi alamiah dalam kegiatan-kegiatan yang menunjukkan peran KUA Kecamatan Tepus dalam penguatan ketahanan keluarga. Data kemudian diperoleh dengan observasi partisipatif, wawancara mendalam kepada insforman dari KUA serta dokumentasi kantor tentang semua hal yang berkaitan dengan obyek penelitian. Tugas kepenghuluan dari KUA Kecamatan Tepus telah mendukung perannya dalam penguatan ketahanan keluarga dalam masyarakat yang berkaitan ketahanan agama, psikologis dan sosiologis serta ekonomi masyarakat.
\end{abstract}

Kata Kunci: peran, Kantor Urusan Agama, ketahanan keluarga,

\begin{abstract}
This research is related to the role of KUA in the realization of family resilience (tahaga) in the life of the Muslim community in Tepus sub-district in Gunung Kidul Regency. The benefits can be felt in the mapping of external factors in family resilience that can affect life, including social conditions and community participation. Judging from its nature, this qualitative sociojuridical research includes descriptive research which intends to provide as accurate a data as possible about natural conditions in activities that show the role of KUA Tepus District in strengthening family resilience. The data were then obtained by participatory observation, in-depth interviews with informants from the KUA and office documentation on all matters relating to the object of research. The Kepenghuluan task of KUA Tepus District has supported its role in strengthening family resilience in the community related to religious, psychological and sociological resilience as well as the community's economy.
\end{abstract}

Keywords: role, family resilience, Office of Religious Affairs 
lin Suny Atmaja, Andrie Irawan, Zainul Arifin, Ihab Habudin,

Nur Mukhlish Zakariya, Syawal Rusmanto

\section{Pendahuluan}

Arti penting ketahanan keluarga (selanjutnya disebut dengan tahaga) telah muncul sejak Pelita VI tahun 1994 dan telah disepakati bahwa, "keluarga menjadi institusi pembangunan serta berperan menyiapkan sumber daya pembangunan yang berkualitas". (BKKBN 1995:52-53) PP Nomor 21 Tahun 1994 tentang Penyelenggaraan Pembangunan Keluarga Sejahtera menegaskan arti penting Keluarga sejahtera bagi bangsa Indonesia. Dalam UU Nomor 52 Tahun 2009 tentang Perkembangan Kependudukan dan Pembangunan Keluarga, menyatukan pengertian tahaga dengan kesejahteraan keluarga (Nasution dan Nasution 2017; RI 2009).

Tahaga juga dikenal dengan family strength atau family resilience. Hal itu bersangkutan dengan kemampuan pribadi maupun keluarga untuk memanfaatkan potensinya untuk menghadapi tantangan hidup, termasuk kemampuan untuk mengembalikan fungsi-fungsi keluarga seperti semula dalam menghadapi tantangan dan krisis. konsepnya holistik yang merangkai alur pemikiran suatu sistem, mulai dari kualitas ketahanan sumberdaya dan strategi koping. Tahaga merupakan proses dinamis dalam keluarga untuk melakukan adaptasi positif terhadap bahaya dari luar dan dari dalam keluarga.

Di perundangan yang sama pada Bab I pasal 1 ayat 6 pengertian keluarga sendiri ditentukan sebagai "unit terkecil dalam masyarakat yang terdiri dari suami istri; atau suami, istri dan anaknya; atau ayah dan anaknya (duda), atau ibu dan anaknya (janda)" ketentuan lain menyebutnya, "unit terkecil dari masyarakat yang terdiri atas kepala keluarga dan beberapa orang yang terkumpul dan tinggal di suatu tempat di bawah suatu atap dalam keadaan saling ketergantungan." (Iwan 2009:23). Empat sifat melekat di dalamnya, yaitu: kumpulan orang yang menyatu dalam ikatan pernikahan, darah, maupun adopsi; hidup bersama-sama secara tetap dalam satu atap rumah tangga (Sunarti 2003). Keluarga dalam hal ini dilihat sebagai subsistem dalam masyarakat (unit terkecil dalam masyarakat) yang saling berinteraksi dengan subsistem lainnya untuk mempertahankan keseimbangan sosial dalam masyarakat (Muchtaromah 2008:293). 
Hal ini menunjukkan bahwa komunikasi kuat antar pihak dalam keluarga yang bisa membawa kepada tujuan bersama krusial untuk diserukan bagi siapa yang sedang terlibat di dalamnya. Al Amin (2018) telah menyebutkan keterbatasan tingkat intensitas pertemuan antar anggota keluarga karena kegiatan di luar rumah bisa berdampak buruk. Hubungan buruk pun bisa terjadi karena intervensi yang berlebihan terhadap kehidupan keluarga anak bisa berdampak pada perceraian (Nafi dan Al-Amin 2018).

Dalam mewujudkan suatu pola tahaga, hakikat keluarga sebagai suatu rangkaian sistem yang berkaitan dan berhubungan kuat tidak bisa diabaikan selain komunikasi. Pertimbangan bersifat alami semata juga tidak bisa diandalkan. Semua faktor harus ditinjau, dan kekuatan yang ada di sekitarnya wajib dipandang. Nilai, norma, sikap maupun tingkah laku, maupun situasi dan kondisi lain yang ada di masyarakat adalah penting bagi penciptaan tahaga. Saefullah, Giyasih, dan Setiyawati (2018) juga sudah memastikan dalam penelitiannya beberapa dukungan sosial yang berkontribusi signifikan terhadap ketahanan keluarga dari berbagai perspektif anggota keluarga tenaga kerja di Indonesia. Perspektif anak mendapat sokongan secara instrumental dari luar sumber dukungan sosial. Sang istri dukungan lingkungan masyarakat secara instrumental. Dalam pandangan yang sama, suami maupun orang tua terbantu dari penghargaan yang diberikan oleh masyarakat.

Megawangi kemudian menyimpulkan dari Zeitlin dan Garman sebagai kemampuan keluarga dalam mengelola sumber daya yang mereka miliki serta menanggulangi masalah yang dihadapi untuk dapat memenuhi kebutuhan fisik maupun psikosial keluarga. Karenanya ada yang mengatakannya sebagai sebagai kemampuan keluarga untuk menangkal atau melindungi diri dari berbagai permasalahan atau ancaman kehidupan baik yang datang dari dalam keluarga itu sendiri maupun dari luar keluarga seperti lingkungan, komunitas, masyarakat, maupun negara (Kemenpppa RI 2017).

Dari dua pendapat diatas, unsur-unsur yang terliput dalam tahaga antara lain; pengelolaan sumber daya manusia, pemecahan masalah dan pemenuhan kebutuhan. Adapun indikasinya bisa ditinjau dari; 
"1) perwujudan sikap saling melayani sebagai tanda kemuliaan;

2) Adanya keakraban antara suami dan istri menuju kualitas perkawinan yang baik; 3) Adanya orang tua yang mengajar dan melatih anak-anaknya dengan berbagai tantangan kreatif, pelatihan yang konsisten, dan mengembangkan keterampilan; 4) Adanya suami dan istri yang memimpin seluruh anggota keluarganya dengan penuh kasih sayang; 5) Adanya anak-anak yang mentaati dan menghormati orang tuanya" (Kemenpppa RI 2017:7).

Hasanah (Hasanah 2019) kemudian menyejajarkan tahaga dengan konsep keluarga sakīnah, mawaddah, dan rahmah dalam perwujudan rumah tangga Islam. Hal yang sama diutarakan oleh Nurdin (Nurdin 2019) untuk dipertahankan dalam kehidupan berkeluarga. Pancaran dari kalbu itu hanya bisa muncul dalam berbagai kegiatan kerumahtanggaan yang berkomitmen (Lubis 2018). Semua pihak didalamnya telah diatur dalam Quran untuk terlibat dengan tanggung jawab (Hisyam et al. 2019). Hudud Allah dalam Kitab suci yang menjamin keterlaksanan ketahanan keluarga harus dihormati oleh semua pribadi dalam keluarga (Anwar dan Santoso 2017).

Tahaga kemudian dibagi dalam lima aspek kehidupan, yaitu ketahanan agama, fisik, psikis, ekonomi, dan ketahanan sosial. Puspitawati telah menjabarkannya secara mendalam.

"1)Ketahanan agama adalah kemampuan keluarga dalam meningkatkan keyakinan beragama dalam bentuk menjalankan ibadah, Indonesia sebagai Negara beragama tentu saja ketahanan agama ini penting, karena berkembangnya paham ateisme dan komunisme bisa membahayakan kelangsungan hidup sebuah keluarga bahkan negara, ibadah merupakan kebutuhan dasar manusia untuk bisa bersyukur kepada Tuhan, karena dengan kedekatan kepada Tuhan maka keluarga akan mampu mengatasi persoalan. 2) Ketahanan fisik ialah kemampuan keluarga dalam menjaga kesehatan fisik, karena bila fisiknya tidak sehat, maka akan menjadi masalah dan berdampak kepada kondisi psikis kehidupan keluarga.3) Ketahanan psikologis keluarga terdiri kemampuan anggota keluarga untuk mengelola kesehatan mentalnya, baik dalam mengelola emosinya, mengelola stress, motivasi hidup, komunikasi dengan anggota keluarga, sehingga anggota keluarga dalam berkembang dan menjalankan fungsinya dengan baik, karena banyak di dapati beberapa kasus perceraian terjadi karena persoalan komunikasi dan kesehatan mental pasangan yang bermasalah. 4) Ketahanan ekonomi berupa kemampuan 
keluarga dalam memenuhi kebutuhan hidupnya, baik kebutuhan pangan, sandang, papan dan hiburan, ketahanan ekonomi cukup penting karena keluarga yang tidak terpenuhi kebutuhan hidupnya dengan baik akan berdampak kepada kualitas hidup dan cara menyelesaikan masalah keluarga. 5) Ketahanan sosial atau kekuatan keluarga dalam penerapan nilai, budaya dan norma dalam masyarakat, ketahanan sosial meliputi bagaimana sebuah keluarga berinteraksi dengan lingkungan sosial, karena dengan hubungan sosial yang sehat maka sebuah keluarga dapat berkembang dengan baik dan mampu beradaptasi dengan lingkungan di manapun dia berada sehingga kehidupan keluarga dapat berjalan dengan baik" (Puspitawati 2012).

Kantor Urusan Agama (KUA) kemudian tidak bisa menjauhkan diri dalam perwujudan tahaga dalam kehidupan umat Islam di Indonesia. Sebagai lembaga public yang berwenang penuh dalam pencatatan pernikahan Islam dan pelestariannya, maka tahaga harus menjadi perhatiannya. Berbagai aktivitas bisa dilaksanakan agar permasalahan pernikahan umat dalam yurisdiksi masing KUA bisa diselesaikan secara baik dan benar dalam menjamin kehidupan keluarga. Intervensi dalam kerumahtanggaan olehnya pun dimungkinkan. KUA harus meminimalisir poligami agar tidak merugikan salah satu pihak (Asmorohadi 2018). Mereka juga harus menekan pernikahan usia dini (Wafiq dan Santoso 2017; Zainuri et al. 2019). Kemenag RI wilayah Yogyakarta selaku payung kelembagaan KUA juga telah menyatakan komitmennya untuk berpartisipasi dalam gerakan tahaga Di Indonesia (Putra 2019).

Dalam perspektif tahaga, penelitian terhadap peran KUA mewujudkannya dalam perkawinan warga muslim di kecamatan Tepus di Kabupaten Gunung Kidul. Hal ini mengingat kondisi sosio ekonomis dan geografis dari kecamatan berpegunungan itu berada di wilayah yang tidak sama dengan kota lainnya di Propinsi DIY. Hal ini sekaligus untuk memetakan aspek-aspek kehidupan yang bisa menjadi peluang bagus bagi KUA berperan besar dalam tahaga menjadi lebih baik di wilayahnya. Penelitian demikian paralel dengan anjuran dari Musfiroh et al. (2019) untuk penelitian lebih lanjut tentang factor eksternal yang bisa berpengaruh dalam tahaga termasuk kondisi sosial dan partisipasi masyarakat.

\section{Metode Penelitian}


lin Suny Atmaja, Andrie Irawan, Zainul Arifin, Ihab Habudin,

Nur Mukhlish Zakariya, Syawal Rusmanto

Dilihat dari sifatnya, penelitian yuridis kualitatif ini termasuk penelitian deskriptif yang bermaksud dalam pemberian data yang seteliti mungkin tentang manusia, keadaan atau gejala-gejala lainnya (Soekanto 2007:10). Deskripsi secara alamiah ditujukan kepada kegiatan-kegiatan yang menunjukkan peran KUA Kecamatan Tepus dalam penguatan ketahanan keluarga. Data kemudian diperoleh dengan observasi partisipatif, wawancara mendalam kepada insforman dari KUA serta dokumentasi kantor tentang semua hal yang berkaitan dengan obyek penelitian.

\section{Peran Kepenghuluan dalam Penguatan Tahaga}

KUA memiliki wewenang dalam pernikahan masyarakat muslim. Administrasi pernikahan adalah tugas yang umum dikenal oleh masyarakat umum. Kegiatan lain yang berkaitan dengan pembinaan perkawinan juga banyak dilakukan untuk mendukung wewenang administrasinya.

Tabel 1

Daftar Pernikahan, Rujuk, Talak Dan Cerai Tahun 2017

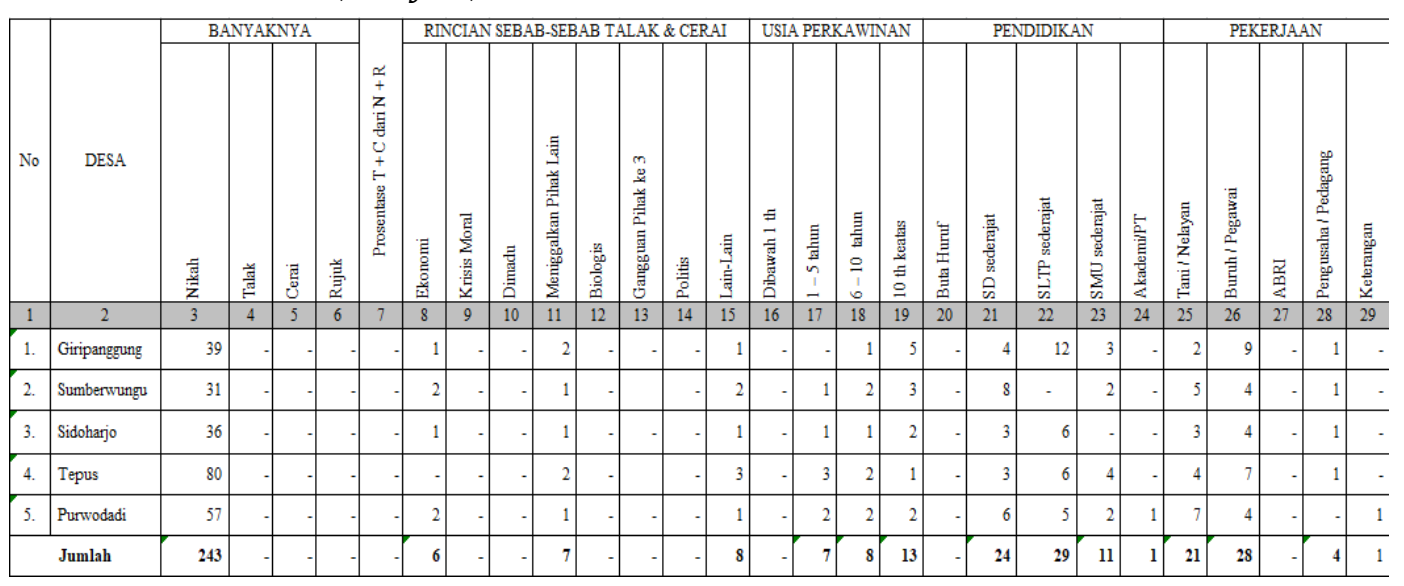

Bimbingan Perkawinan (Binwin).

Bimbingan Perkawinan secara tatap muka bagi calon pengantin dilaksanakan untuk mendukung rencana kerja pemerintah di bidang pembangunan tahaga menuju keluarga sakinah. Keluarga merupakan pondasi penting dalam pembangunan sumber daya manusia. Dalam pertuannya dijelaskan bahwa kegiatan itu guna mendukung tahaga yang kokoh dan tangguh sebagai kebutuhan mendasar negara, hal ini sejalan dengan agenda prioritas pembangunan dalam meningkatkan kualitas hidup manusia Indonesia (Kemenag RI 2017). 


\title{
Gambar 1
}

Dokumentasi Bimbingan Perkawinan

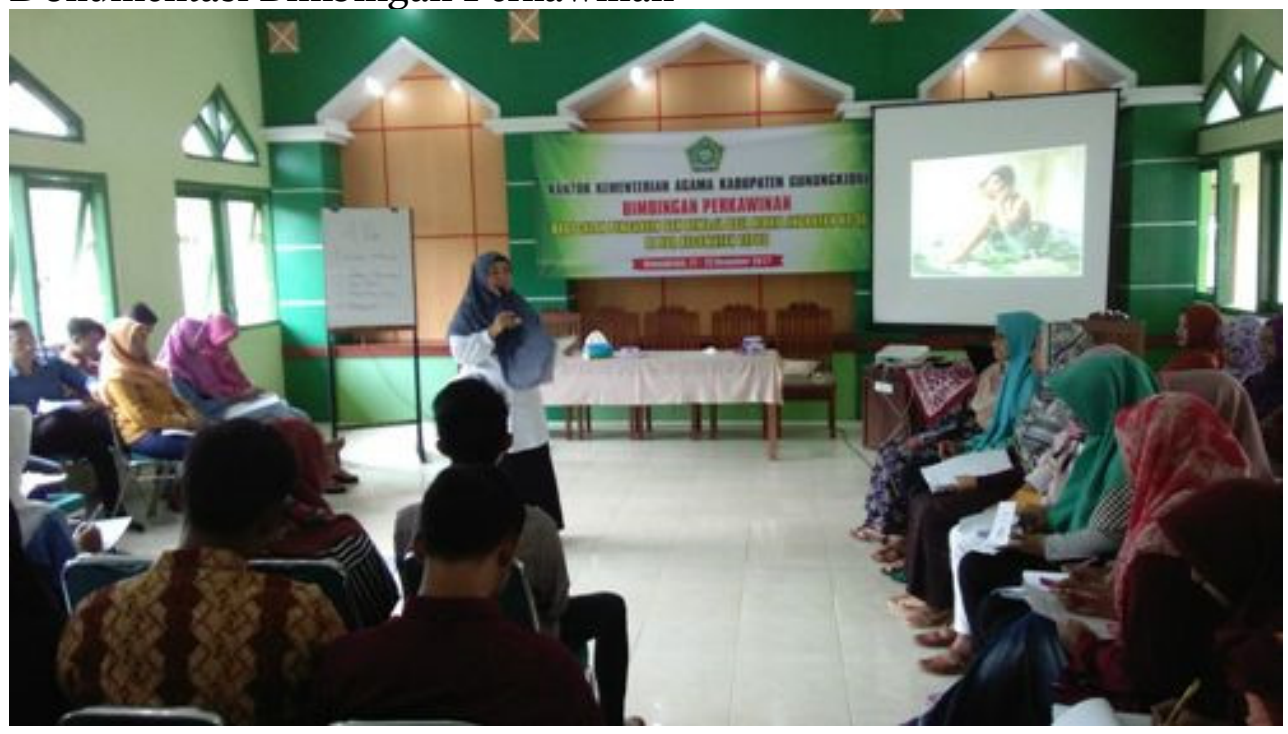

Sumber: KUA Kecamatan Tepus

Program Binwin berjalan selama 16 JPL bagi Calon Pengantin merupakan salah satu bentuk peran KUA dalam penguatan tahaga di Kecamatan Tepus yang materi penasehatan dan bimbingan mengenai dinamika perkawinan, kebutuhan keluarga, pengelolaan konflik, serta pendidikan anak.

\begin{abstract}
"Program Bimbingan Perkawinan bagi Calon Pengantin merupakan salah satu wujud nyata kesungguhan KUA dalam dalam penguatan tahaga di Kecamatan Tepus. Adapun materi penasehatan dan bimbingan yang kita sampaikan mengenai dinamika perkawinan, kebutuhan keluarga, pengelolaan konflik, serta pendidikan anak. Dengan materi-materi tersebut, harapan kami para calon pengantin memiliki modal pemahaman tentang keluarga" (Djajuli 2018).
\end{abstract}

Pelaksanaannya dengan modul yang telah ditetapkan dari Kemenag RI. Pengisi materi utama sering berasal internal KUA yang dikenal dikenal dengan fasilitator perkawinan. Aturan juga telah menganjurkan untuk mengundang pemateri dari luar lembaga yang berkaitan (Kemenag RI 2017)

\section{Kursus Calon Pengantin (Suscatin)}

Calon pengantin yang sudah memenuhi syarat sebagaimana yang diatur dalam undang-undang pernikahan maupun yang diatur dalam aturan agama, harus mengikuti kursus calon pengantin dengan membawa permohonan untuk dikursus calon pengantin dan untuk mendapatkan materi 
lin Suny Atmaja, Andrie Irawan, Zainul Arifin, Ihab Habudin,

Nur Mukhlish Zakariya, Syawal Rusmanto

bimbingan oleh petugas yang ditugaskan oleh pengurus Badan Penasehat Pembinaan dan Pelestarian Perkawinan (BP4). Pelaksanaan akad nikah dilaksanakan oleh Kepala KUA atau penghulu, itu dimulai dari persiapan yang pertama adalah kesiapan calon pengantin, apakah mereka betul mau nikah atau tidak? Kalau betul-betul siap maka calon pengantin memulai mempersiapkan surat-surat yang diperlukan di pemerintah setempat, mulai ditingkat RW/RT, Kelurahan, Kecamatan, atau langsung ke KUA setempat dimana akad nikah akan dilaksanakan.

Pelayanan kursus calon pengantin dilakukan dua kali dalam satu minggu, adapun tema materi yang disampaikan, yakni; a)Dasar dan tujuan pernikahan baik berdasarkan peraturan perundang-undangan maupun berdasarkan ajaran agama Islam; b)Syarat, Rukun dan Larangan pernikahan; c)Hak dan kewajiban suami istri; d) Upaya pembentukan keluarga sakinah untuk; perwujudan harmonisasi hubungan suami istri; pembinaan hubungan antara anggota keluarga serta lingkungan; pembinaan kesejahteraan keluarga, dan kehidupan beragama dalam keluarga

"Suscatin bagian dari upaya KUA Kecamatan Tepus dalam penguatan tahaga. Pelayanannya dilakukan dua kali dalam satu minggu; yaitu hari Selasa dan Kamis. Adapun materinya meliputi nasehat-nasehat pernikahan seperti cara melestarikan pernikahan, bagaimana membentuk keluarga yang sakinah mawaddah warahmah. Intinya diberikan pengetahuan dalam berumah tangga tangga yang baik. Sepasang calon suami isteri diberi informasi singkat tentang kemungkinan yang akan terjadi dalam rumah tangga, sehingga pada saatnya nanti dapat mengantisipasi masalah keluarga dengan baik. Mewanti-wanti jauh hari agar masalah yang timbul kemudian dapat diminimalisir dengan baik, untuk itu bagi remaja usia nikah atau calon pengantin sangat perlu mengikuti pembekalan singkat (short course) dalam bentuk kursus pra nikah yang merupakan salah satu upaya penting dan strategis. Kursus ini menjadi sangat penting dan vital sebagai bekal bagi kedua calon pasangan untuk memahami secara subtansial tentang seluk beluk kehidupan keluarga dalam berumah tangga" (Sutamta 2018). 
Kursus Pra Nikah

Untuk mewujudkan tahaga perlu dilakukan kursus pra nikah bagi remaja usia nikah. Kursus Pra Nikah adalah pemberian bekal pengetahuan, pemahaman, keterampilan dan penumbuhan kesadaran kepada remaja usia nikah tentang kehidupan rumah tangga dan keluarga. Remaja usia nikah dimaksud adalah laki-laki muslim berumur sekurang-kurangnya 19 tahun dan perempuan muslimah 16 tahun.

Tujuan dilaksanakan kursus pra nikah adalah untuk meningkatkan pemahaman dan pengetahuan tentang kehidupan rumah tangga/keluarga dalam mewujudkan keluarga sakinah, mawaddah warahmah serta mengurangi angka perselisihan, perceraian, dan kekerasan dalam rumah tangga. Dengan tercapainya tujuan tersebut maka tahaga akan terbangun dengan kokoh (Kemenag RI 2013).

Di kecamatan Tepus, kursus pra nikah dilaksanakan di beberapa sekolah di wilayah kecamatan Tepus dan remaja masjid di masjid-masjid kecamatan Tepus. Adapun materi kursus pra nikah meliputi Peraturan Perundangan tentang perkawinan dan pembinaan keluarga, Hukum Munakahat, Pelaksanaan fungsi-fungsi keluarga, Merawat Cinta Kasih dalam Keluarga, Manajemen Konflik dalam Keluarga, Psikologi perkawinan dan keluarga. Materi-materi tersebut disampaikan dengan metode ceramah, diskusi, tanya jawab, study kasus (simulasi) dan penugasan yang pelaksanaannya dapat disesuaikan dengan kondisi dan kebutuhan di lapangan (Djajuli 2018).

Penyuluhan Rutin

Peranan KUA Kecamatan Tepus tidak hanya sebatas pada saat pra nikah, namun pembinaan dan penyuluhan harus terus dilaksanakan dengan melaksanakan kunjungan rutin ke masyarakat melalui pengajian, khutbah jumat dan majelis taklim. Penyuluhan secara tatap muka ini sangat baik dalam menjembatani masyarakat dengan penyuluh sebagai representasi pemerintah dalam memecahkan persoalan public yang berkaitan dengan bidang keagamaan. Komunikasi tatap muka demikian telah dipuji oleh 
lin Suny Atmaja, Andrie Irawan, Zainul Arifin, Ihab Habudin,

Nur Mukhlish Zakariya, Syawal Rusmanto

Supratman et al. (2019) dalam kecepatan penyelesaian dan kepuasan masyarakat terhadap pelayanan public.

Hal ini dapat dilakukan karena setiap KUA memiliki perangkat berupa petugas Penyuluh Agama fungsional dan Penyuluh Agama non PNS yang bertugas di setiap desa. Hal ini dilaksanakan untuk mewujudkan tahaga di setiap rumah tangga dalam kerangka bina desa keluarga Sakinah (Nurkholis, Istifianah, dan Rahman 2020; Zulhijja 2018). Materi penyuluhan juga mencakup aktivitas keagamaan wakaf yang berkaitan dengan wewenang KUA (Sukarno et al. 2019)

Penyuluhan demikian tidak semata berkaitan dengan sosialisasi nilai perkawinan tetapi berkaitan antara taklim agama secara keseluruhan dengan pembinaan tahaga dalam meningkatkan kualitas spiritual bagi seluruh anggota keluarga. Materinya mendalami aspek spiritual untuk memperluas cakupan tahaga dalam diri keluarga dapat terwujud, demikian harapannya. Aspek spiritual yang dimaksud adalah ibadah seluruh anggota keluarga, aktif mengikuti ceramah agama, wirid, doa dan zikir bersama.

Muatan penyuluhan juga berkaitan pemenuhan kebutuhan material yang sangat mempengaruhi tercapainya tahaga adalah peningkatan kualitas. Sumber Daya Keluarga (SDK) yang mencakup aspek ekonomi, yang merupakan dasar material, yang menjadi tempat majelis taklim memainkan perannya. Aspek ekonomi yang digali adalah aktivitas majelis taklim dalam melaksanakan arisan, melakukan kegiatan gotong royong dan saling bekerjasama dalam kehidupan sesama anggota.

Bila kedua aspek spiritual dan material telah cukup terpenuhi, maka selanjutnya upaya mewujudkan tahaga dapat segera terealisir. Ukurannya adalah seluruh anggota keluarga taat menjalankan ibadah sehari-hari, sopan santun anggota keluarga terjaga dengan baik, kebutuhan material rumah tangga terpenuhi dengan baik, komunikasi antara sesama anggota keluarga tercipta dengan baik serta anggota keluarga berperan aktif dalam aktivitas sosial di tengah masyarakat.

Pembinaan tahaga ditekankan kepada penguatan iman dengan implementasi moral Islam dalam berkeluarga. Materi kedua kemudian 
berkaitan dengan bagaimana ketaatan anggota keluarga dalam menjalankan ibadah shalat sehari-hari, sikap sopan santun anggota keluarga, kemampuan memenuhi kebutuhan material anggota keluarga, terciptanya komunikasi yang baik antar sesama anggota keluarga serta keaktifan anggota keluarga dalam aspek sosial keagamaan di tengah masyarakat.

Sejalan dengan pemikiran Puspitawati (2012), intervensi KUA dalam tahaga masyarakat kecamatan Tepus didominasi dalam bidang agama, sosial dan psikologi keluarga, meski ketahanan ekonomi juga diperhatikan pada kegiatan tertentu seperti majelis taklim. Perkawinan dan ritual keseharian sebagai ibadah menjadi tekan penting untuk menjadi kebutuhan dasar agar syukur kepada Tuhan menjadi hal lazim dalam kehidupan berkeluarga dalam mengatasi persoalannya. Pengembalian masalah dengan iman berkaitan dengan ketenangan psikologis keluarga dimana masing-masing pribadi dalam keluarga siap dalam mensikapi kesehatan mental masing-masing secara baik meski dalam tingkat tekanan hidup yang tinggi. Iman juga diharapkan memberikan pedoman dalam bersosialisasi. Utamanya saat menerapkan nilai, budaya dan norma dalam masyarakat saat berinteraksi dengan lingkungannya.

\section{Penutup}

Keberhasilan dalam pelaksanaan tugas kepenghuluan dari KUA Kecamatan Tepus dalam mendukung perannya dalam penguatan keluarga tidak terlepas dari dari beberapa hal yang mendukungnya. Perannya dalam ketahanan agama, psikologis dan sosiologis serta ekonomi masyarakat tidak bisa lepas dari harapan dan dukungan masyarakat terhadap penguatan ketahanan keluarga sangat besar. Keterbukaan dalam hubungan kerjasama yang sinergis dengan berbagai organisasi atau lembaga kemasyarakatan yang memiliki visi dan misi yang sama. Dukungan dari instansi pemerintah lainnya dalam mewujudkan institusi keluarga yang bahagia berdasarkan Ketuhanan YME. Jumlah sarana ibadah Islam yang tersebar di wilayah Kecamatan Tepus pun sangat banyak dalam mendukung peran penguatan tahaga dari KUA Kecamatan Tepus. 
lin Suny Atmaja, Andrie Irawan, Zainul Arifin, Ihab Habudin,

Nur Mukhlish Zakariya, Syawal Rusmanto

\section{Daftar Pustaka}

Amin, M. N. K. A1. 2018. "Komunikasi Sebagai Upaya Untuk Membangun Ketahanan Keluarga Dalam Kajian Teori Nilai Etik." Al-Ahwal: Jurnal Hukum Keluarga Islam 11(1):79-90.

Anwar, Ahmad Kasyful, dan Triwibowo Budi Santoso, ed. 2017. Fondasi Keluarga Sakinah Bacaan Mandiri Calon Pengantin. Jakarta: Kemenag RI.

Asmorohadi. 2018. "Pernikahan Poligami Di Wilayah Administrasi Kantor Urusan Agama Kecamatan Playen Tahun 2012-2015." Ulumuddin: Jurnal Ilmu-ilmu Keislaman 8(2):79-97.

BKKBN. 1995. Opini Keluarga Sejahtera. Jakarta: BKKBN.

Djajuli, Ahmad. 2018."wawancara."

Hasanah, Diah. 2019. "Alquran dan Ketahanan Keluarga: Studi Kasus di Lembaga Konsultasi Keluarga PERSISTRI (Persatuan Islam Istri)." Journal Of Qur'an And Hadith Studies 8(1):56-73.

Hisyam, Muhammad Ridho, Suyanto, Muhammad Sadzili, Zainul Arifin, dan Ahmad Syafi'i Rahman. 2019. "Peran Anggota Keluarga Berketahanan Dalam Perspektif Quran." Ulumuddin: Jurnal Ilmu-ilmu Keislaman 9(2):171-86.

Iwan, Sugeng. 2009. Pengasuhan Anak Dalam Keluarga "The Next Lost Generation." Jakarta: Lembaga Kajian Agama dan Jender, Solidaritas Perempuan.

Kemenag RI. 2013. Peraturan Direktur Jenderal Bimbingan Masyarakat Islam Nomor: Dj.II/542 Tahun 2013 Tentang Pedoman Penyelenggaraan Kursus Pra Nikah.

Kemenag RI. 2017. Keputusan Direktur Jenderal Bimbingan Masyarakat Islam Nomor 373 tahun 2017 Tentang Bimbingan Perkawinan Bagi Calon Pengantin.

Kemenpppa RI. 2017. Pembangunan Ketahanan Keluarga 2016. Jakarta: CV Lintas Katulistiwa.

Lubis, Amany. 2018. Ketahanan Keluarga Dalam Perspektif Islam. Jakarta: Majelis Ulama Indonesia.

Muchtaromah, Bayyinatul. 2008. Pendidikan Reproduksi bagi Anak Menuju Akil Baligh. Malang: UIN Malang Press.

Musfiroh, Mujahidatul, Sri Mulyani, Erindra Budi Cahyanto, Angesti Nugraheni, dan Ika Sumiyarsi. 2019. "Analisis Faktor-Faktor Ketahanan Keluarga Di Kampung KB RW 18 Kelurahan Kadipiro Kota Surakarta." PLACENTUM: Jurnal Ilmiah Kesehatan dan Aplikasinya 7(2):61-66.

Nafi, Ahmad Zuhri, dan M. Nur Kholis Al-Amin. 2018. "Perceraian Karena Intervensi Orang Tua terhadap Rumah Tangga Anak." Ulumuddin: Jurnal Ilmu-ilmu Keislaman 8(2):115-30.

Nasution, Khoiruddin, dan Syamruddin Nasution. 2017. "Peraturan dan Program Membangun Ketahanan Keluarga: Kajian Sejarah Hukum." Asy-Syir'ah: Jurnal Ilmu Syari'ah dan Hukum 51(1):1-23.

Nurdin, Nurdin. 2019. "Konsep Pembinaan Dan Pertahanan Keluarga Dalam Perspektif Islam." Psikoislamedia : Jurnal Psikologi 4(1):1-12.

Nurkholis, Nurkholis, Istifianah Istifianah, dan A. Syafi'i Rahman. 2020. "Peran Penyuluh Agama dalam Program Desa Binaan Keluarga Sakinah Di Desa Dlingo." Nuansa Akademik: Jurnal Pembangunan Masyarakat 
$5(1): 25-36$.

Puspitawati, Irene. 2012. Ketahanan dan kesejahteraan keluarga: Konsep dan Realita di Indonesia. Bogor: IPB Press.

Putra, Bramma Aji. 2019. "Kabid Nadhif: Bersama Kita Kuatkan Ketahanan Keluarga dengan Akida - Website Kementerian Agama RI Kanwil DIY." Diambil (https://diy.kemenag.go.id/11022-kabid-nadhifbersama-kita-kuatkan-ketahanan-keluarga-dengan-akida.html).

RI. 2009. Undang-undang No. 52 Tahun 2009 tentang Perkembangan Kependudukan dan Pembangunan Keluarga.

Saefullah, Lalu, Sri Rum Giyasih, dan Diana Setiyawati. 2018. "Pengaruh Dukungan Sosial Terhadap Ketahanan Keluarga Tenaga Kerja Indonesia." Jurnal Sosiologi Pendidikan Humanis 3(2):119-32.

Soekanto, Soerjono. 2007. Pengantar Penelitian Hukum,. Jakarta: UI Press.

Sukarno, Sukarno, Supriyono Supriyono, Miftachul Alfin, Fattah Setiawan, Moh. Shofiyul Huda MF, dan Busyro Busyro. 2019. "Analisis Implementasi Wakaf Tanah di Kecamatan Pandak Kabupaten Bantul." Nuansa Akademik: Jurnal Pembangunan Masyarakat 4(2):133-44.

Sunarti, Euis. 2003. Perumusan Ukuran Ketahanan Keluarga (Measurement of Family Strenght). Bogor: Institut Pertanian Bogor.

Supratman, Bawa, Fatah Nashir, A. S. Rahman, Zainul Arifin, dan Cipto Sembodo. 2019. "Pelaksanaan Jaring Aspirasi Sebagai Komunikasi Publik Pemerintah Daerah Kabupaten Kulon Progo." Nuansa Akademik Jurnal Pembangunan Masyarakat 4(1):1-16.

Sutamta. 2018."wawancara."

Wafiq, Ahmad, dan F. Setiawan Santoso. 2017. "Upaya Yuridis Dan Sosiologis Kantor Urusan Agama Dalam Pencegahan Pernikahan Usia Dini." Ulumuddin: Jurnal Ilmu-ilmu Keislaman 7(1):17-30.

Zainuri, M. Sulkhan, Hartoyo, Muhajir, MNK Al Amin, Andri Irawan, dan Iin Sunny Atmadja. 2019. "Analisis Penyebab Pernikahan Usia Dini Di Kecamatan Pleret Kabupaten Bantul." Nuansa Akademik Jurnal Pembangunan Masyarakat 4(1):33-46.

Zulhijja. 2018."wawancara." 
lin Suny Atmaja, Andrie Irawan, Zainul Arifin, Ihab Habudin, Nur Mukhlish Zakariya, Syawal Rusmanto 